\title{
Induced pluripotent stem cells as a cellular model for studying Down Syndrome
}

\author{
Brigida $\mathrm{AL}^{1}$, Siniscalco $\mathrm{D}^{1}$
}

Down Syndrome (DS), or Trisomy 21 Syndrome, is one of the most common genetic diseases. It is a chromosomal abnormality caused by a duplication of chromosome 21. DS patients show the presence of a third copy (or a partial third copy) of chromosome 21 (trisomy), as result of meiotic errors. These patients suffer of many health problems, such as intellectual disability, congenital heart disease, duodenal stenosis, Alzheimer's disease, leukemia, immune system deficiencies, muscle hypotonia and motor disorders. About one in 1000 babies born each year are affected by DS. Alterations in the dosage of genes located on chromosome 21 (also called HSA21) are responsible for the DS phenotype. However, the molecular pathogenic mechanisms of DS triggering are still not understood; newest evidences suggest the involvement of epigenetic mechanisms. For obvious ethical reasons, studies performed on DS patients, as well as on human trisomic tissues are limited. Some authors have proposed mouse models of this syndrome. However, not all the features of the syndrome are represented. Stem cells are considered the future of molecular and regenerative medicine. Several types of stem cells could provide a valid approach to offer a potential treatment for some untreatable human diseases. Stem cells also represent a valid system to develop new cell-based drugs and/or a model to study molecular disease pathways. Among stem cell types, patient-derived induced pluripotent stem (iPS) cells offer some advantages for cell and tissue replacement, engineering and studying: self-renewal capacity, pluripotency and ease of accessibility to donor tissues. These cells can be reprogrammed into completely different cellular types. They are derived from adult somatic cells via reprogramming with ectopic expression of four transcription factors (Oct3/4, Sox2, c-Myc and Klf4; or, Oct3/4, Sox2, Nanog, and Lin28). By reprogramming cells from DS patients, it is possible to obtain new tissue with the same genetic background, offering a valuable tool for studying this genetic disease and to design customized patient-specific stem cell therapies.

Key Words: Induced pluripotent stem cells; Down Syndrome; Cell transplantation; Disease modeling

\section{Introduction: an overview on Down Syndrome}

Down Syndrome (DS), also called trisomy 21, is the most intensively studied human aneuploidy condition. It was first described by Dr. John Langdon Down in the $19^{\text {th }}$ century $^{[1]}$. Epidemiologic studies show an incidence of 1 in 1000 live births, with the risk of having a child with trisomy 21 increases with maternal age ${ }^{[2]}$.

DS is due to a chromosomal abnormality, specifically a duplication of chromosome 21. Most people (95\%) with DS show the presence of a third copy of chromosome $21^{[3,4]}$, which means that each cell in the body has three copies of chromosome 21 instead of the usual two copies. This condition is caused mainly by the failure of chromosome 21 to properly segregate during oogenesis ${ }^{[5]}$. In about $5 \%$ of patients, one copy of chromosome 21 is translocated to another acrocentric chromosome, most often chromosome 14 or $21^{[3,4]}$. This translocation may occur during the formation of reproductive cells (eggs and sperm) in a parent or in the fetus very early in development. If the family has other cases with DS or the mother is at an age considered at risk, prospective parents need to carry out an examination of their karyotypes in order to determine whether one of the two parents is the putative carrier of a balanced translocation.
Mosaicism is the rarest type of DS which accounts for $2-4 \%$ of patients with $\mathrm{DS}^{[6]}$. This form of genetic disorder is caused by problems after fertilization, during the phase where cells are dividing rapidly. The individual with this type of DS has two types of cells: those with 46 chromosomes (the normal number), and those with 47 chromosomes (as occurs in DS).

DS can be diagnosed before birth. Currently, there are two types of test for DS: screening tests and diagnostic tests. Screening tests estimate the chance of the fetus to have DS, whereas diagnostic tests can identify whether the baby has DS. The American College of Obstetricians and Gynecologists recommends providing the option of screening tests and diagnostic tests for DS to all pregnant women, regardless of the age $e^{[7]}$.

Screening tests include the first trimester combined test, the integrated screening test, and the cell-free fetal DNA analysis. The first trimester combined test includes a maternal blood test and an ultrasound analysis (also called sonography). In the maternal blood test, two different markers are investigated: pregnancy-associated plasma protein-A (PAPP-A) and human chorionic gonadotropin (HCG). Abnormal levels of PAPP-A or HCG can indicate a problem with the baby. In the ultrasound analysis, measurements are made on a specific area on the back of the neck of the child. This test is known 
as a nuchal translucency screening test. When the child has abnormalities, more fluid than usual tends to collect in this neck tissue. The results of ultrasound and blood tests combined with the mother's age can produce an estimate of the risk of having a baby with DS.

The integrated screening test includes the features of the first trimester combined test with a maternal blood test to measure the levels of four pregnancy-associated substances: alpha fetoprotein, estriol, HCG and inhibin A. This test can achieve the same sensitivity of detection as the first trimester combined test, but with a lower false-positive rate. The cell-free fetal DNA test checks for fetal DNA circulating in the mother's blood. If this screening test indicates a high risk of DS, diagnostic tests should be used.

There are also several diagnostic tests that are able to identify DS. These include:

-Amniocentesis. It uses the amniotic fluid to analyze the chromosomes of the fetus. This test is performed after 15 weeks of pregnancy. The test is associated with a slight risk of miscarriage.

-Chorionic villus sampling (CVS). In CVS, cells are taken from the placenta and used to analyze the fetal chromosomes. This test is performed after 10 weeks of pregnancy and it has a higher risk of miscarriage than amniocentesis.

-Cordocentesis. The fetal blood is taken from a vein in the umbilical cord and examined for chromosomal defects. This test is performed between 18 and 22 weeks of pregnancy. It has a higher risk of miscarriage than amniocentesis and chorionic villus sampling, so it is only recommended when results of other tests are unclear and the desired information cannot be obtained by any other method.

Individuals with DS have the particular phenotypic features that include intellectual disability, short stature, motor disorders, and characteristic facies ${ }^{[8]}$. In addition to these features, these patients have specific major congenital malformations, such as atrioventricular septal defect of the heart, duodenal stenosis or atresia, and imperforate anus of the gastrointestinal tract.

People with DS have a higher risk of developing Alzheimer's disease, acute lymphoblastic leukemia (ALL) and acute myeloid leukemia (AML) $)^{[9,10]}$. The incidence of ALL is 20 -fold higher in children with DS than in the general population, and the incidence of AML is between 46 - to 83 -fold higher, with a particular susceptibility to acute megakaryoblastic leukemia ${ }^{[11]}$.

Both the phenotypes and the pathological conditions associated with DS are due to alterations in the dosage of genes located on chromosome HSA21. However, the molecular pathogenic mechanisms of DS induction are still not understood. Newest evidences suggest the involvement of epigenetic mechanisms. Indeed, in response to changes in gene dosage, trisomy could disrupt normal epigenetic marks across the genome. Distinct DNA methylation pattern on chromosome 21 seems to be associated with accelerated cognitive aging in DS patients ${ }^{[12]}$.

The quality of life of people with DS is compromised by multiple health problems affecting them. The patients are treated by "early intervention programs" to promote development and independence individually, as recommended by the US National DS Society (NDSS). Some of the therapies used in the "early intervention programs" are:

Physical therapy includes exercises to help the child develop good posture, increasing muscle strength, and improving balance.

Speech-language therapy can help DS children by improving their communication skills by using language more effectively.
Occupational therapy helps finding ways to adjust everyday tasks and conditions to match a person's needs and abilities.

Emotional and behavioral therapies. Children with DS may become frustrated because of difficulty communicating, may develop compulsive behaviors, Attention Deficit Hyperactivity Disorder, and other mental health issues. Therapists identify the cause of these behaviors to develop a strategy for avoiding or preventing these situations and teach better or more positive ways to respond to situations ${ }^{[13]}$.

Sometimes in addition to these non-drug therapies, patients with DS assume amino acid supplements or drugs that affect their brain activity.

\section{Down Syndrome animal model}

For obvious ethical reasons, studies performed on DS patients, as well as on human trisomic tissues are limited. Some authors have proposed mouse models of this syndrome. The mouse model more used to study the DS is Ts65Dn mouse. It bears segmental trisomy for a distal region of the mouse chromosome Mmu16 which contains approximately $55 \%$ of Hsa21 conserved genes ${ }^{[14]}$. This model is additionally trisomic for approximately 50 genes that are nonorthologous to Hsa2 $1^{[15]}$. Ts65Dn mouse, although it is an invaluable tool for the study DS, provides only a limited representation of human T21 syndrome modelling. Indeed, this mouse model has limitations including the lack of numerous Hsa21 orthologous genes and the addition of some Mmu17 genes that are non-trisomic in humans. These differences in genes may confound results of therapeutic interventions. Since these males are sterile, mice must be generated from Ts65Dn dams.

These limitations could be overcome studying stem cells in vitro. Among stem cell types, patient-derived induced pluripotent stem (iPS) cells can be used as in vitro human disease models ${ }^{[16,17]}$.

These cells can be reprogrammed into completely different cellular types, differentiation into various cellular types can provide new insights into disease pathophysiology that are not possible with murine models ${ }^{[18,19]}$. The next paragraph will explain in detail the advantages of using this type of stem cells.

\section{Induced Pluripotent Stem (iPS) Cells}

Stem cells are considered the future of molecular and regenerative medicine $^{[20]}$. Several types of stem cells could provide a valid approach to offer a potential treatment for some untreatable human diseases $^{[21]}$. Stem cells also represent a valid system to develop new cell-based drugs and/or a model to study molecular disease pathways. Among stem cell types, patient-derived induced pluripotent stem (iPS) cells offer some advantages for cell and tissue replacement, engineering and studying self-renewal capacity, pluripotency, and ease of accessibility to donor tissues ${ }^{[22]}$. These cells, discovered by the Nobel Prize winner S. Yamanaka, can be reprogrammed into completely different cellular types ${ }^{[23]}$. They are derived from adult somatic cells via reprogramming with ectopic expression of four transcription reprogramming factors (Oct3/4, Sox2, c-Myc and Klf4; or, Oct3/4, Sox2, Nanog, and Lin28, otherwise known as Yamanaka's cocktail). The expression of the Yamanaka's cocktail transcription factors lead to the suppression of the genes responsible for differentiation, together with the expression of genes and epigenetic changes which sustain pluripotency, in this way reverting the cells to a pluripotent state ${ }^{[24]}$.

Yamanaka's research team was the first to generate iPS cells from mouse embryonic and adult fibroblasts by retrovirus-mediated transfection of four transcription factors under embryonic stem cell (ESC) culture conditions ${ }^{[24]}$. In this work, they paved the way to 
overcome the problems related to the use of ESCs for cell transplantation. Indeed, the use of human embryos is accompanied by several ethical issues, as well as scientific problems, such as tissue rejection following transplantation in patients, in vivo teratoma formation and uncontrollable cell proliferation of undifferentiated $\mathrm{ESCs}^{[25,26]}$. The generation of pluripotent cells directly from the patients' own cells could resolve these ESC limitations. Yamanaka's group successfully demonstrated efficacious reprogramming of differentiated human somatic cells into a pluripotent state. Human somatic cell-derived iPS cells are comparable to human ESCs in many aspects including morphology, proliferation, cell markers, gene expression, in vitro differentiation capacity and teratoma formation ${ }^{[27]}$. The technology for iPS cells generation is simple and reproducible, thus providing hope for potential human disease treatments. However, therapeutic potential of iPS cells remains to be further elucidated. The work of Rudolf Jaenisch's group demonstrated that autologous iPS cells were effective in a humanized sickle cell anemia mouse model ${ }^{[28]}$, opening the way for a possible human transfer of the technology. Beyond cell transplantation, patientderived iPS cells are also useful for modeling diseases. Derivation of patient-specific cells could be a potential cure for many diseases. Indeed, several diseases could be modeled by using iPS cells: from neurological disorders (i.e. Alzheimer's disease, Parkinson's disease, Huntington's disease, spinal muscular atrophy, amyotrophic lateral sclerosis, Duchenne muscular dystrophy, schizophrenia, and autism spectrum disorders) to kidney diseases, metabolic diseases, blood diseases, diabetes and cardiovascular diseases ${ }^{[29-34]}$. In the near future, modeling diseases with iPS cells could overcome or reduce the need for animal disease models, since iPS cell-models represent more accurately the physiology of human cells as compared to animal cells ${ }^{[23]}$. This point is of particular interest in DS research, whereas animal models could be inadequate. It has been demonstrated that in a chromosome rodent model, in which the mice were engineered with the murine chromosome segment orthologous to the DS critical region on HSA21, the human cranial abnormalities commonly associated with trisomy 21 were not seen ${ }^{[35]}$. This result was probably due to the different chromosomal distribution of genetic segments between human and mouse. Indeed, the orthologous segments to human chromosome 21 are located on mouse chromosomes 10 and 17.

\section{Modeling Down Syndrome with Patient-Specific iPS cells}

By reprogramming cells from DS patients, it is possible to obtain new tissue with the same genetic background, offering a valuable tool for studying this genetic disease and to design potential customized patient-specific stem cell therapies. For an efficient DS model, it is necessary that the new cell system is able to reproduce the features of the disease.

In 2008, Park et al., described derivation of human iPS cell lines from two young male DS patients ${ }^{[36]}$. Donor cells were fibroblasts transduced with the four (OCT4, SOX2, KLF4, and c-MYC) reprogramming factors cocktail, via the Maloney murine leukemia virus (MMLV)-derived retroviruses pMXs. Noteworthy, the authors performed analysis of the iPS cell karyotype, showing the characteristic trisomy 21 anomaly. Morphology, pluripotency and differentiation capacity of iPS cells were confirmed. In 2013, Weick et al., reprogrammed fibroblasts from two DS subjects to iPS cells ${ }^{[37]}$. One of the fibroblast lines had low level mosaicism for trisomy 21 . They also differentiated iPS cells into neurons expressing dorsal forebrain neurons markers. These DS iPS cell -derived neurons showed significant synaptic deficits, such as reduced synaptic activity attributable to developmental abnormalities consistent with cognitive deficits in DS patients.

By using lentiviral vectors, dermal fibroblasts from DS patients of various karyotypes (trisomy 21 and translocation) have been reprogrammed into iPS cells. The iPS cells maintained the same karyotypes as the parental human dermal fibroblasts ${ }^{[38]}$.

Hematopoietic disturbances associated with DS have also been modeled using iPS cells. Induced PS cells were differentiated into hematopoietic cells, showing that trisomy 21 is accompanied by an abnormal expansion of hematopoietic progenitor cells ${ }^{[39]}$. Hematopoietic defects have also been detected by Chou et al. ${ }^{[40]}$. Blood progenitor cells generated from DS iPS cells enhanced erythropoiesis and reduced myelopoiesis, even if proliferation rate was normal.

DS iPS cells from fetal fibroblasts of monozygotic twins discordant for trisomy 21 show remarkable differences. The DS vs. normal twin's iPS cells show differences in proliferation, neurogenesis and neuronal differentiation ${ }^{[41]}$.

Astrocytes also take a role in DS pathogenesis. DS patient fibroblasts were reprogrammed into iPS cells and subsequently differentiated to astroglia and neurons ${ }^{[42]}$. Derived astroglia cells showed cellular dysfunction and oxidative stress. They negatively interacted with derived neurons in regard to the regulation of neurite outgrowth, neuronal ion channel maturation, synaptic activity formation and non-cell-autonomous toxic effects on neurons ${ }^{[42]}$. Very importantly, once transplanted in mouse neonatal brain, DS iPS cell-derived astroglia contributed to the impaired brain function ${ }^{[42]}$.

Through these techniques, it has been confirmed that iPS cells generated from DS somatic cells possess the genetic and phenotypic characteristics of the disease. In addition, differentiation of DSderived iPS cells into neural cells still retain cellular dysfunctions, providing evidence that iPS cell system is an efficient model to study the syndrome and to enable discovery of the underlying causes of and pharmaceutical therapeutic treatments for this disorder.

\section{Using Patient-Specific iPS cells for treating Down Syndrome Gene therapy}

In DS research, removal of the trisomy condition is a priority goal. Induced PSC generation from DS patients allows experiments of gene therapy correction. In an elegant research experiment, DS fibroblast-derived iPS cells were engineered by TKNEO fusion gene (a hybrid gene combined by human thymidine kinase (tk) gene and the coding region of the bacterial neomycin-resistance gene $($ neo $))^{[43]}$. Briefly, derived cells showed trisomy removal, providing insights for a future clinical application.

Chromosome therapy has been proposed in the work of Jiang et al. ${ }^{[44]}$. Through a zinc finger nuclease (ZFN)-driven targeted addition, they inserted the human X-inactivation gene, XIST (which produces a non-coding RNA from the inactive $\mathrm{X}$ chromosome) into the trisomic 21chromosome of DS patient-derived iPS cells to enhance epigenetic chromosome-wide changes. XIST induced longrange silencing in iPS cells, and XIST- iPS cell differentiated neural precursor cells showed improved cell proliferation and neurogenesis. This strategy highlights that X-chromosome inactivation via iPS cells could be an useful strategy to correct chromosomal dosage imbalance $^{[45]}$.

\section{Cell-based therapy}

Induced PS cells derived from amniotic fluid stem cells (AFSCs) represent an attractive potential cell system in DS modeling ${ }^{[28]}$. These stem cells are very interesting for cell-based applications, as they show low expression of major histocompatibility complex antigens, high pluripotency, low immunogenicity and anti-inflammatory properties $^{[46]}$. DS AFSC-derived iPS cells retain their cytogenetic signatures and are able to differentiate into specialized hematopoietic 
and neural precursor cells ${ }^{[47,48]}$.Very interestingly, in their work, Lu's group used amniotic stem cells as a source to generate human DS iPS cells $^{[49]}$. Reprogramming was achieved by co-expressing Yamanaka factors through lentiviral delivery. DS iPS cells maintained the abnormal chromosomal karyotype signature and were then differentiated into neuronal progenitor cells (NPCs). These differentiated cells showed amyloid precursor protein (APP) gene over-expression. In addition, DS iPS-NPCs also displayed overexpression of microRNAs miR-155 and miR-802, which in turn trigger methyl-CpG-binding protein 2 (MeCP2) degradation with consequent neurogenesis and neuron maturation impairment.

AFSC- iPS cell system is also a valuable tool for drug screening. DS AFSC iPS cell-derived neural cells treated with $\mathrm{N}$ butylidenephthalide, a major phthalide ingredient of Angelica sinensis, showed a reduction in secreted $\mathrm{A} \beta 40$ deposits in the total and hyperphosphorylated Tau levels ${ }^{[50]}$. This study indicates that DS AFSC- iPS cell derived neural cells can be utilized as both an ideal cellular model of DS with early-onset dementia and as highthroughput screening model of candidate drugs.

What would be the best donor cell type choice for reprogramming? The answer should be based on the use of iPS cells: disease modeling to study the basic mechanism of the disease, drug screening, or cell therapy ${ }^{[51]}$. Due to easy, well-validated cell culture procedures and high proliferation rate, fibroblasts are the most used cell type for the generation of iPS cells. Apart the above mentioned AFSCs, fetal stromal cells and mononuclear cells have been also efficaciously used for reprogramming ${ }^{[52]}$.

Optimal cell culture conditions need to be further improved and standardized. Several improvements in such conditions have been proposed. Dietary supplements (i.e. vitamin C and anti-oxidants) added in the reprogramming media are able to improve iPS cell state ${ }^{[53,54]}$. Serum- and feeder-free defined culture conditions have been also implemented ${ }^{[53]}$. Of course, while looking for new cell culture improvements, proliferation rate, pluripotency and selfrenewal capacity should not be lost.

\section{Limitations}

Using retroviruses, transgenes, or the oncogene c-Myc for cell reprogramming could be a limitation for human applications of iPS cells $^{[55-57]}$. Viral vectors may integrate into the host genome and create single-base (i.e. insertions or deletions) mutations. The following processes should be avoided in order to ensure genomic stability: mutations during reprogramming process, epigenetic reactions, abnormalities in the $\mathrm{X}$ chromosome, and copy number variations. Several other methods have been proposed to overcome the use of integrating viral vectors. These methods are integration free systems: plasmid DNA, recombinant proteins, and synthetic mRNA ${ }^{[58]}$. Transfection of two expression plasmids (one containing the complementary DNAs of Oct3/4, Sox2, and Klf4 and the other containing the c-Myc cDNA) into embryonic fibroblasts results in iPS cells generation without plasmid integration, which produced teratomas when transplanted ${ }^{[59]}$. The expression of the miR302/367 microRNA-cluster is able to give an efficient reprogramming of mouse and human somatic cells to iPS cells, without the use of exogenous transcription factors ${ }^{[60]}$. In addition, whereas miR302/367iPS cells show similar characteristics to transcription factors-iPS cells, in order to produce pluripotency and teratoma formation, miRNAbased reprogramming is two orders of magnitude more efficient than standard Yamanaka's factors-based approach. The
microRNA-induced PS cells have also a reduced risk of mutations and tumorigenesis ${ }^{[61]}$.

Briggs at al., generated non-viral iPS cells from DS fibroblasts by episomal reprogramming ${ }^{[62]}$. These DS iPS cells are able to model in vitro the phenotype of the disorder. Their differentiation toward neural phenotype indicated increased neural cell death due to oxidative stress. Other limitations to be considered are:

-Age of the somatic donor cells. Pluripotency is achieved more easily in young tissue (i.e. embryonic tissue) rather than adult tissue ${ }^{[51]}$.

-Differentiation status of somatic donor cells. Differentiation state could influence reprogramming process. This fact is noteworthy to be considered, as some iPS cells are able to retain the "epigenetic memory" of their primitive tissue ${ }^{[63]}$. It has been demonstrated that hematopoietic stem cells are more efficiently reprogrammed than differentiated $\mathrm{B}$ and $\mathrm{T}$ cells ${ }^{[64]}$. Recently, it has been reported that MUC1, a growth factor receptor of human stem cells acting to maintain the naïve stem cell state ${ }^{[65,66]}$, is able to change the DNA methylation pattern in cancer cells ${ }^{[67,68]}$, also contributing to inflammation state ${ }^{[69]}$.

Novel genome editing technologies could help correct mutations that have arisen during reprogramming process. The clustered regularly interspaced short palindromic repeats (CRISPR)/CRISPR- associated protein 9 nuclease (CRISPR/Cas9) system is an efficient tool to efficaciously edit and correct gene mutations in iPS cells ${ }^{[70]}$.

\section{Conclusions}

By reprogramming cells from DS patients, it is possible to obtain new tissue with the same genetic background, offering a valuable tool for studying this genetic disease and to design customized patient-specific stem cell therapies. However, several limitations still need to be overcome and further experimental validations are required before translation into therapy.

\section{References}

1. Langdon Down J. One some of the mental affections of childhood and youth. J. \& A. Churchill Ed. 1887.

2. Penrose LS. The relative effects of paternal and maternal age in mongolism. J. Genet. 1933; 27: 219.

3. Hook EG. Epidemiology of Down syndrome.In: Pueschel SM, Rynders JE: Down Syndrome. Advances in Biomedicine and the Behavioral Sciences. Cambridge: Ware Press (pub.) 1982. p. 11.

4. Thuline HC, Pueschel SM. Cytogenetics in Down syndrome. In: Pueschel SM, Rynders JE: Down Syndrome. Advances in Biomedicine and the Behavioral Sciences. Cambridge: Ware Press (pub.) 1982. P. 133.

5. Sherman SL, Allen EG, Bean LH, Freeman SB. Epidemiology of Down Syndrome. Ment Retard Dev Disabil Res Rev. 2007;13(3):221-7.

6. Mikkelsen M. Down's syndrome cytogenetic epidemiology. Hereditas. 1977;86(1):45-50.

7. Lejeune J, Gautier M, Turpin R. Etude des chromosomes somatiques de neuf enfants mongoliens. C. R. Acad. Sci. 1959; 248(11):1721-22.

8. American Congress of Obstetricians and Gynecologists [Internet] [cited 2016 May 20]. Available from http:// www.acog.org

9. Antonarakis SE, Lyle R, Dermitzakis ET, Reymond A, Deutsch S. Chromosome 21 and Down syndrome: From genomics to pathophysiology. Nat Rev Genet. 2004;5(10):725-38.

10. Lott IT, Dierssen M. Cognitive deficits and associated neurological complications in individuals with Down's syndrome. Lancet Neurol. 2010;9(6):623-33. 
11. Lange B. The management of neoplastic disorders of haematopoeisis in children with Down's syndrome. Br J Haematol. 2000;110(3):512-24.

12. Jones MJ, Farré P, McEwen LM, Macisaac JL, Watt K, Neumann SM, Emberly E, Cynader MS, Virji-Babul N1, Kobor MS. Distinct DNA methylation patterns of cognitive impairment and trisomy 21 in Down syndrome. BMC Med Genomics. 2013;6:58.

13. National Down Syndrome Society[Internet] - [cited 2016 May 20]. Available from http://www.ndss.org

14. Davisson MT, Schmidt C, Akeson EC. Segmental trisomy of murine chromosome16: a new model system for studying Down syndrome. Prog Clin Biol Res. 1990;360:263-80.

15. Rueda N, Flórez J, Martínez-Cué C. Mouse models of Down syndrome as a tool to unravel the causes of mental disabilities. Neural Plast. Neural Plast. 2012;2012:584071.

16. Marchetto MC, Carromeu C, Acab A, Yu D, Yeo GW, Mu Y, Chen G, Gage FH, Muotri AR. A model for neural development and treatment of Rett syndrome using human induced pluripotent stem cells. Cell. 2010;143(4):527-39.

17. Yagi T, Ito D, Okada Y, Akamatsu W, Nihei Y, Yoshizaki T, Yamanaka S, Okano H, Suzuki N. Modeling familial Alzheimer's disease with induced pluripotent stem cells. Hum Mol Genet. 2011 Dec 1;20(23):4530-9.

18. Park IH, Arora N, Huo H, Maherali N, Ahfeldt T, Shimamura A, Lensch MW, Cowan C, Hochedlinger K, Daley GQ. Diseasespecific induced pluripotent stem cells. Cell. 2008;134(5):877-86.

19. Ito D, Okano H, Suzuki N. Accelerating progress in induced pluripotent stem cell research for neurological diseases. Ann Neurol. 2012;72(2):167-74.

20. Siniscalco D, Giordano A, Galderisi U. Novel insights in basic and applied stem cell therapy. J Cell Physiol. 2012;227(5):2283-6.

21. Siniscalco D, Pandolfi A, Galderisi U. State-of-the-art on basic and applied stem cell therapy; Stem Cell Research Italy-International Society for Cellular Therapy Europe, Joint Meeting, Montesilvano (PE)-Italy, June 10-12, 2011. Stem Cells Dev. 2012;21(5):668-9.

22. Siniscalco D, Cirillo A, Antonucci N. Nobel Prize to Inducent Pluripotent Stem Cells and Cloning: A Milestone for the Regenerative Medicine. J Regen Med. 2012; 1:2.

23. Seah YF, El Farran CA, Warrier $T$, Xu J, Loh YH. Induced Pluripotency and Gene Editing in Disease Modelling: Perspectives and Challenges. Int J Mol Sci. 2015;16(12):28614-34.

24. Takahashi K, Yamanaka S. Induction of pluripotent stem cells from mouse embryonic and adult fibroblast cultures by defined factors. Cell. 2006;126(4):663-76

25. Siniscalco D, Giordano C, Galderisi U, Luongo L, Alessio N, Di Bernardo G, de Novellis V, Rossi F, Maione S. Intra-brain microinjection of human mesenchymal stem cells decreases allodynia in neuropathic mice. Cell Mol Life Sci. 2010;67(4):65569.

26. Lee AS, Tang C, Cao F, Xie X, van der Bogt K, Hwang A, Connolly AJ, Robbins RC, Wu JC. Effects of cell number on teratoma formation by human embryonic stem cells. Cell Cycle.2009;8(16):2608-12.

27. Takahashi K, Tanabe K, Ohnuki M, Narita M, Ichisaka T, Tomoda $\mathrm{K}$, Yamanaka S. Induction of pluripotent stem cells from adult human fibroblasts by defined factors. Cell. 2007;131(5):861-72.

28. Hanna J, Wernig M, Markoulaki S, Sun CW, Meissner A, Cassady JP, Beard C, Brambrink T, Wu LC, Townes TM, Jaenisch R. Treatment of sickle cell anemia mouse model with iPS cells generated from autologous skin. Science. 2007;318(5858):1920-23.

29. Russo FB, Cugola FR, Fernandes IR, Pignatari GC, Beltrão-Braga PC.Induced pluripotent stem cells for modeling neurological disorders.World J Transplant. 2015;5(4):209-21.

30. Freedman BS. Modeling Kidney Disease with iPS Cells. Biomark Insights. 2015;10(Suppl 1):153-169.

31. Balboa D, Otonkoski T. Human pluripotent stem cell based islet models for diabetes research. Best Pract Res Clin Endocrinol Metab. 2015;29(6):899-909.
32. Talkhabi M, Aghdami N, Baharvand H. Human cardiomyocyte generation from pluripotent stem cells: A state-of-art. Life Sci. 2016;145:98-113.

33. Rashid ST, Corbineau S, Hannan N, Marciniak SJ, Miranda E, Alexander G, Huang-Doran I, Griffin J, Ahrlund-Richter L, Skepper J, Semple R, Weber A, Lomas DA, Vallier L. Modeling inherited metabolic disorders of the liver using human induced pluripotent stem cells. J Clin Invest. 2010;120(9):3127-36.

34. Ye Z, Zhan H, Mali P, Dowey S, Williams DM, Jang YY, Dang CV, Spivak JL, Moliterno AR, Cheng L. Human-induced pluripotent stem cells from blood cells of healthy donors and patients with acquired blood disorders. Blood. 2009;114(27):547380

35. Olson LE, Richtsmeier JT, Leszl J, Reeves RH. A chromosome 21 critical region does not cause specific Down syndrome phenotypes. Science. 2004;306(5696):687-90

36. Park IH, Arora N, Huo H, Maherali N, Ahfeldt T, Shimamura A Lensch MW, Cowan C, Hochedlinger K, Daley GQ. Diseasespecific induced pluripotent stem cells. Cell. 2008; 134(5):877-86.

37. Weick JP, Held DL, Bonadurer GF 3rd, Doers ME, Liu Y, Maguire C, Clark A, Knackert JA, Molinarolo K, Musser M, Yao L, Yin Y, Lu J, Zhang X, Zhang SC, Bhattacharyya A. Deficits in human trisomy 21 iPSCs and neurons. Proc Natl Acad Sci U S A. 2013;110(24):9962-67.

38. Mou X, Wu Y, Cao H, Meng Q, Wang Q, Sun C, Hu S, Ma Y, Zhang H. Generation of disease-specific induced pluripotent stem cells from patients with different karyotypes of Down syndrome. Stem Cell Res Ther. 2012;3(2):14.

39. Maclean GA, Menne TF, Guo G, Sanchez DJ, Park IH, Daley GQ, Orkin SH. Altered hematopoiesis in trisomy 21 as revealed through in vitro differentiation of isogenic human pluripotent cells. Proc Natl Acad Sci U S A. 2012;109(43):17567-72.

40. Chou ST, Byrska-Bishop M, Tober JM, Yao Y, Vandorn D, Opalinska JB, Mills JA, Choi JK, Speck NA, Gadue P, Hardison RC, Nemiroff RL, French DL, Weiss MJ. Trisomy 21-associated defects in human primitive hematopoiesis revealed through induced pluripotent stem cells. Proc Natl Acad Sci U S A. 2012;109(43):17573-78

41. Hibaoui Y, Grad I, Letourneau A, Sailani MR, Dahoun S, Santoni FA, Antonarakis SE, Feki A. Modelling and rescuing neurodevelopmental defect of Down syndrome using induced pluripotent stem cells from monozygotic twins discordant for trisomy 21. EMBO Mol Med. 2014;6(2):259-77.

42. Chen $C$, Jiang P, Xue H, Peterson SE, Tran HT, McCann AE, Parast MM, Li S, Pleasure DE, Laurent LC, Loring JF, Liu Y, Deng W. Role of astroglia in Down's syndrome revealed by patient-derived human-induced pluripotent stem cells. Nat Commun. 2014;5:4430.

43. Li LB, Chang KH, Wang PR, Hirata RK, Papayannopoulou T, Russell DW. Trisomy correction in Down syndrome induced pluripotent stem cells. Cell Stem Cell. 2012; 11(5):615-19.

44. Jiang J, Jing Y, Cost GJ, Chiang JC, Kolpa HJ, Cotton AM, Carone DM, Carone BR, Shivak DA, Guschin DY, Pearl JR, Rebar EJ, Byron M, Gregory PD, Brown CJ, Urnov FD, Hall LL, Lawrence JB. Translating dosage compensation to trisomy 21 . Nature. 2013; 500(7462):296-300.

45. Lawrence J, Telfer C. Interview: from Down's syndrome to basic epigenetics and back again. Epigenomics. 2013;5(6):611-614.

46. Slamecka J, Salimova L, McClellan S, van Kelle M, Kehl D, Laurini J, Cinelli P, Owen L, Hoerstrup SP, Weber B. Nonintegrating episomal plasmid-based reprogramming of human amniotic fluid stem cells into induced pluripotent stem cells in chemically defined conditions. Cell Cycle. 2016; 15(2):234-49.

47. Zhou J, Wang D, Liang T, Guo Q, Zhang G. Amniotic fluidderived mesenchymal stem cells: characteristics and therapeutic applications. Arch Gynecol Obstet. 2014; 290(2):223-31. 
48. Pipino C, Mukherjee S, David AL, Blundell MP, Shaw SW, Sung $\mathrm{P}$, Shangaris $\mathrm{P}$, Waters JJ, Ellershaw $\mathrm{D}$, Cavazzana $\mathrm{M}$, Mostoslavsky G, Pandolfi A, Pierro A, Guillot PV, Thrasher AJ, De Coppi P. Trisomy 21 mid-trimester amniotic fluid induced pluripotent stem cells maintain genetic signatures during reprogramming: implications for disease modeling and cryobanking. Cell Reprogram. 2014;16(5):331-44.

49. Lu HE, Yang YC, Chen SM, Su HL, Huang PC, Tsai MS, Wang $\mathrm{TH}$, Tseng CP, Hwang SM. Modeling neurogenesis impairment in Down syndrome with induced pluripotent stem cells from Trisomy 21 amniotic fluid cells. Exp Cell Res. 2013; 319(4):498-505.

50. Chang CY, Chen SM, Lu HE, Lai SM, Lai PS, Shen PW, Chen PY, Shen CI, Harn HJ, Lin SZ, Hwang SM, Su HL. Nbutylidenephthalide attenuates Alzheimer's disease-like cytopathy in Down syndrome induced pluripotent stem cell-derived neurons. Sci Rep. 2015; 5:8744.

51. Hibaoui Y, Feki A. Concise Review: Methods and Cell Types Used to Generate Down Syndrome Induced Pluripotent Stem Cells. J Clin Med. 2015; 4(4):696-714.

52. Rony IK, Baten A, Bloomfield JA, Islam ME, Billah MM, Islam $\mathrm{KD}$. Inducing pluripotency in vitro: recent advances and highlights in induced pluripotent stem cells generation and pluripotency reprogramming. Cell Prolif. 2015;48(2):140-56.

53. Singh VK, Kumar N, Kalsan M, Saini A, Chandra R. Mechanism of Induction: Induced Pluripotent Stem Cells (iPSCs). J Stem Cells. 2015; 10(1):43-62.

54. Yamasaki S, Taguchi Y, Shimamoto A, Mukasa H, Tahara H, Okamoto T. Generation of human induced pluripotent stem (Ips) cells in serum- and feeder-free defined culture and TGF-B1 regulation of pluripotency. PLoS One. 2014;9(1):e87151.

55. Yu J, Hu K, Smuga-Otto K, Tian S, Stewart R, Slukvin II, Thomson JA. Human induced pluripotent stem cells free of vector and transgene sequences. Science. 2009; 324(5928):797-801.

56. Tagde A, Rajabi H, Bouillez A, Alam M, Gali R, Bailey S, Tai YT, Hideshima T, Anderson K, Avigan D, Kufe D. MUC1-C drives MYC in multiple myeloma. Blood. 2016; 127(21):2587-97.

57. Bouillez A, Rajabi H, Pitroda S, Jin C, Alam M, Kharbanda A, Tagde A, Wong KK, Kufe D. Inhibition of MUC1-C Suppresses MYC Expression and Attenuates Malignant Growth in KRAS Mutant Lung Adenocarcinomas. Cancer Res. 2016; 76(6):1538-48.

58. Singh VK, Kalsan M, Kumar N, Saini A, Chandra R. Induced pluripotent stem cells: applications in regenerative medicine, disease modeling, and drug discovery. Front Cell Dev Biol. 2015; $3: 2$.

59. Okita $K$, Nakagawa $M$, Hyenjong H, Ichisaka T, Yamanaka S. Generation of mouse induced pluripotent stem cells without viral vectors. Science. 2008;322(5903):949-53.
60. Anokye-Danso F, Trivedi CM, Juhr D, Gupta M, Cui Z, Tian Y, Zhang Y, Yang W, Gruber PJ, Epstein JA, Morrisey EE. Highly efficient miRNA-mediated reprogramming of mouse and human somatic cells to pluripotency. Cell Stem Cell. 2011; 8(4):376-88.

61. Miyazaki S, Yamamoto H, Miyoshi N, Takahashi H, Suzuki Y, Haraguchi N, Ishii H, Doki Y, Mori M. Emerging methods for preparing iPS cells. Jpn J ClinOncol. 2012; 42(9):773-79.

62. Briggs JA, Sun J, Shepherd J, Ovchinnikov DA, Chung TL, Nayler SP, Kao LP, Morrow CA, Thakar NY, Soo SY, Peura T, Grimmond S, Wolvetang EJ. Integration-free induced pluripotent stem cells model genetic and neural developmental features of down syndrome etiology. Stem Cells. 2013;31(3):467-48.

63. Kim K, Zhao R, Doi A, Ng K, Unternaehrer J, Cahan P, Huo H, Loh YH, Aryee MJ, Lensch MW, Li H, Collins JJ, Feinberg AP, Daley GQ. Donor cell type can influence the epigenome and differentiation potential of human induced pluripotent stem cells. Nat Biotechnol. 2011;29(12):1117-9.

64. Eminli S, Foudi A, Stadtfeld M, Maherali N, Ahfeldt T, Mostoslavsky G, Hock H, HochedlingerK. Differentiation stage determines potential of hematopoietic cells for reprogramming into induced pluripotent stem cells. Nat Genet. 2009;41(9):968-76.

65. Hikita ST, Kosik KS, Clegg DO, Bamdad C. MUC1* mediates the growth of human pluripotent stem cells. PLoS One. 2008; 3(10): 3312

66. Smagghe BJ, Stewart AK, Carter MG, Shelton LM, Bernier KJ, Hartman EJ, Calhoun AK, Hatziioannou VM, Lillacci G, Kirk BA, DiNardo BA, Kosik KS, Bamdad C. MUC1* ligand, NM23-H1, is a novel growth factor that maintains human stem cells in a more naïve state. PLoS One. 2013;8(3):e58601.

67. Rajabi H, Tagde A, Alam M, Bouillez A, Pitroda S, Suzuki Y, Kufe D. DNA methylation by DNMT1 and DNMT3b methyltransferases is driven by the MUC1-C oncoprotein in human carcinoma cells. Oncogene. 2016 [Epub ahead of print].

68. Hasegawa M, Takahashi H, Rajabi H, Alam M, Suzuki Y, Yin L, Tagde A, Maeda T, Hiraki M, Sukhatme VP, Kufe D. Functional interactions of the cystine/glutamate antiporter, CD44v and MUC1-C oncoprotein in triple-negative breast cancer cells. Oncotarget. 2016; 7(11):11756-69.

69. Takahashi H, Jin C, Rajabi H, Pitroda S, Alam M, Ahmad R, Raina D, Hasegawa M, Suzuki Y, Tagde A, Bronson RT, Weichselbaum R, Kufe D. MUC1-C activates the TAK1 inflammatory pathway in colon cancer. Oncogene. 2015; 34(40):5187-97.

70. Yang Y, Zhang X, Yi Li, Hou Z, Chen J, Kou X, Zhao Y, Wang H, Sun XF, Jiang C, Wang Y, Gao S. Naïve Induced Pluripotent Stem Cells Generated From $\beta$-Thalassemia Fibroblasts Allow Efficient Gene Correction With CRISPR/Cas9. Stem Cells Transl Med. 2016;5(1):8-19.

\author{
Abbreviations \\ AML: Acute myeloid leukemia \\ ALL: Acute lymphoblastic leukemia \\ AFSCs: Amniotic fluid stem cells \\ APP: Amyloid precursor protein \\ CVS: Chorionic villus sampling \\ CRISPR: Clustered regularly interspaced short palindromic repeats \\ DS: Down Syndrome \\ ESC: Embryonic stem cell \\ HCG: Human chorionic gonadotropin \\ iPS: Induced pluripotent stem cells \\ MeCP2: Methyl-CpG-binding protein 2 \\ MUC1: Mucin protein 1 \\ MMLV: Murine leukemia virus \\ NPC: Neuronal progenitor cells \\ PAPP-A: Pregnancy-associated plasma protein-A \\ tk: $\quad$ Thymidine kinase \\ ZFN: Zinc finger nuclease
}




\section{Potential Conflicts of Interests}

\section{None}

\section{Acknowledgments}

The Authors gratefully thank Dr. Stephen Schultz, Department of Physiology, University of Texas Health Science Center San Antonio, TX - USA for editing and suggestions.

\section{Corresponding Author}

Dario Siniscalco, Department of Experimental Medicine, Second University of Naples, Via S. Maria di Costantinopoli, 16 - 80138 Napoli, Italy. Email: dariosin@uab.edu 